\title{
Application of linear motors in mechatronic devices
}

\author{
László Gogolák \\ University of Szeged, Faculty of Engineering, \\ Technical Department, \\ Szeged, Hungary, \\ gogolak@mk.u-szeged.hu
}

\author{
Igor Fürstner \\ Óbuda University, Donát Bánki Faculty of Mechanical and \\ Safety Engineering, \\ Institute of Mechanical Engineering and Security Sciences, \\ Budapest, Hungary \\ furstner.igor@bgk.uni-obuda.hu
}

\author{
Dániel Nyitri \\ Subotica Tech - College of Applied Sciences, \\ Subotica, Serbia \\ nyitri.danie194@gmail.com
}

\begin{abstract}
Nowadays linear motion can be achieved in many different ways, traditional and new. Based on this, it is of great importance to know the advantages and disadvantages of different technologies in use. In this paper, traditional pneumatic and mechanical linear actuators are compared with the new linear motor technologies, which are used in mechatronic devices. Differences between various linear actuator types are studied, and a discussion is presented regarding their characteristics.
\end{abstract}

\section{Keywords—Mechatronic devices, Linear motors, Actuators}

\section{INTRODUCTION}

Nowadays mechatronic devices are gaining more ground in multiple areas. Large number of devices contain more and more mechatronic elements [1]. These devices have multiple sensors and actuators. The most widely used actuators are rotating motors, which are used for achieving both linear and rotational movements. They are well developed and studied in detail. Usually rotational motion is converted to linear motion, or the well-known pneumatic/hydraulic systems are used for linear motion. These solutions usually offer a simple and cheap way to achieve the linear motion with good precision and performance. However, there are multiple different options to achieve linear movement. Among these, linear motors are starting to appear as a potential option for solving the problem of linear motion. The linear motor's characteristics are similar to the conventional systems, but this system has additional positive attributes, which makes it a desirable solution.

This paper gives a brief overview of the linear motors and their applications. Also, a comparison with the well-known linear motion systems is presented.

\section{ELECTROMECHANICAL LINEAR SOLUTIONS}

Often, pneumatic cylinders are used for achieving linear motion, although they usually only have two end positions. This can be improved by using servo pneumatics [2], which offers more precision and better resolution for controlling the pneumatic cylinder [3]. A more efficient alternative to these systems is the electro mechanic solution, which converts the rotation of the electric motor to linear motion. The three most popular types of electro mechanic solution are spindle, toothed and pinion rack based systems. They offer acceptable speed, acceleration and precision, low cost as well as a wide force range and stroke conditions.

\section{A. Spindle based linear solution}

The spindle based linear solutions are one of the oldest and most commonly used ways to convert rotary motion to linear. The screw spindle is connected to the electric motor making the nut slide in two possible directions (Fig. 1) [4]. This system has the highest load losses among linear transformers [5]. This system offers high accuracy to the expense of speed. The spindle based linear actuators are most commonly used in solutions where the accuracy is more important than speed. The operating speed ranges between $60 \mathrm{~mm} / \mathrm{sec}$ and $1060 \mathrm{~mm} / \mathrm{sec}$. Advantages include high repetition accuracy (up to $3 \mu \mathrm{m}$ ) and high working force, ranging from $300 \mathrm{~N}$ to $5400 \mathrm{~N}$ [6].

\section{B. Toothed belt based solution}

The toothed belt based linear actuator uses an electric motor to control the toothed belt, which carries the nut (Fig. 2) [7]. This type of linear actuator offers higher speed, between $1 \mathrm{~m} / \mathrm{s}$ and $10 \mathrm{~m} / \mathrm{s}$. This system is used when speed is more important than accuracy.

The system has lower repetition accuracy (lower than $80 \mu \mathrm{m}$, and weaker load force, which ranges between $300 \mathrm{~N}$ and $2500 \mathrm{~N}$ [8]. By this, the solution falls behind the others. The stroke length is matched with the other mentioned types.

\section{Pinion rack linear solution}

The pinion rack linear actuator is a commonly used, high power device. The unit's speed ranges from $1 \mathrm{~m} / \mathrm{s}$ to $3 \mathrm{~m} / \mathrm{s}$. With the average repetition accuracy (around $50 \mu \mathrm{m}$ ) and very high load force $(2000 \mathrm{~N}$ to $15000 \mathrm{~N})$ [8]. This unit is used when high load is needed on a particularly infinite length, since the stroke length depends only on the length of the rack. 


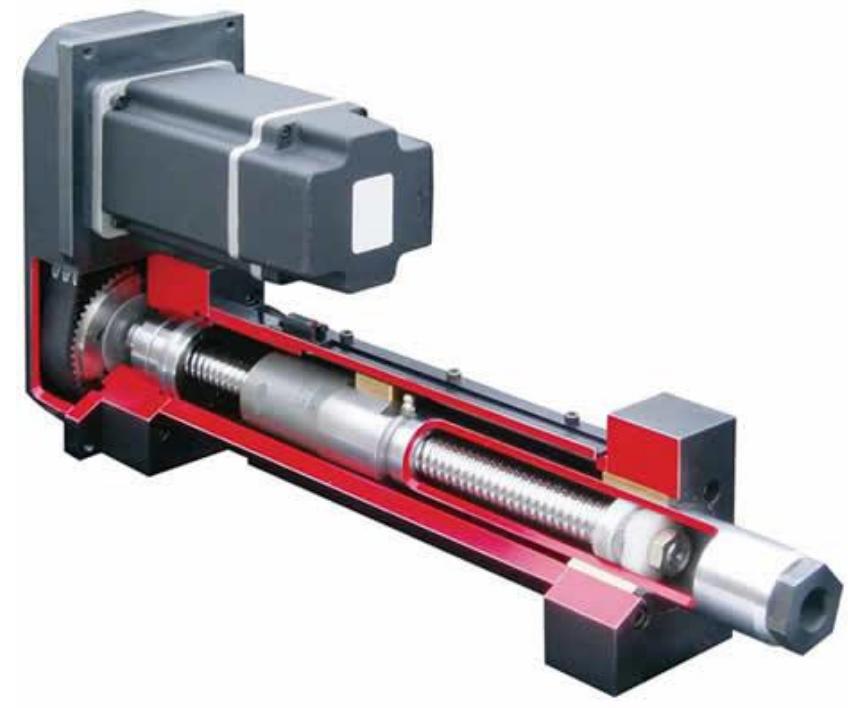

Fig. 1. Spindle based linear drive

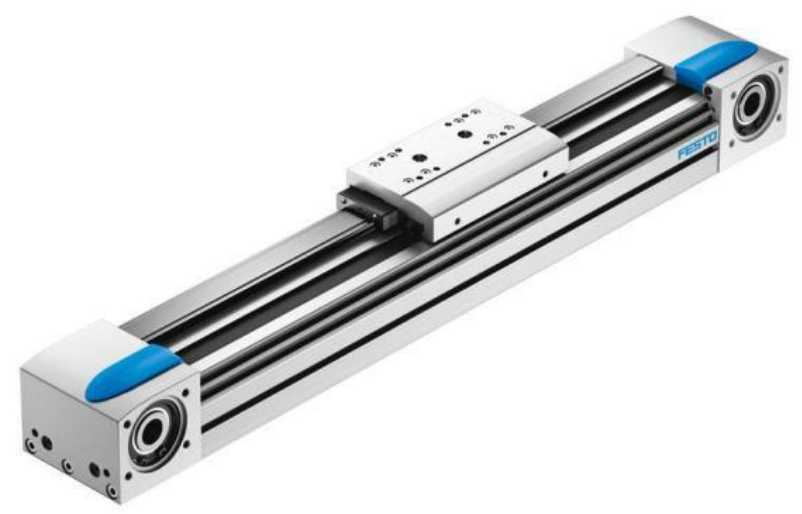

Fig. 2. Toothed belt based linear drive

\section{LINEAR MOTORS}

The basic principle of the linear motor was known in 1895, but the first functioning model was developed in 1947. It can be imagined as an unfolded rotating motor. There are different types of linear motors, including step by step, DC, AC induction, iron cored and ironless brushless DC linear motors, and tubular linear motors [9].

\section{A. Step by step linear motor}

In the linear motor family this type gives the cheapest solution for positioning. This is the most frequently used type, because of its simple structure and controllability (Fig. 3) [10]. It can be referred to as a linear synchronous motor with a permanent magnet.

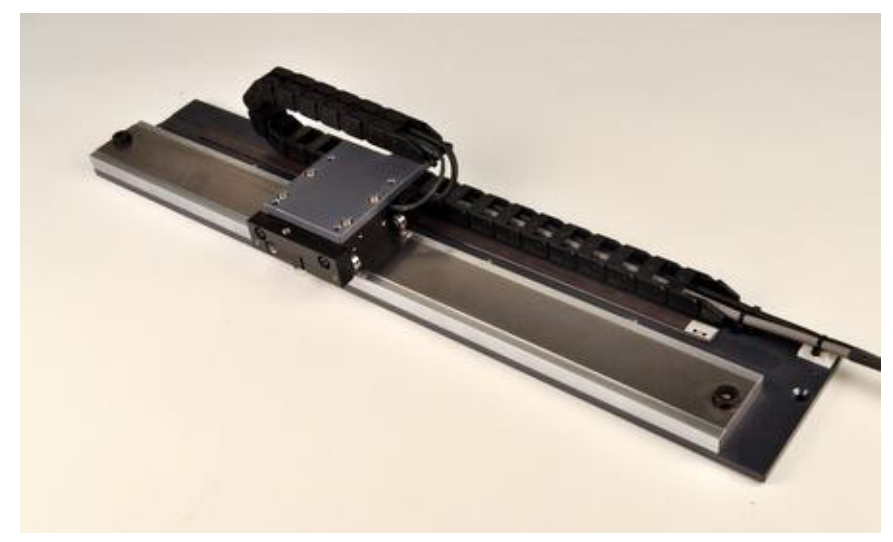

Fig. 3. Step by step linear motor

The two main parts of the motor are the stator, which is a toothed rail, and a rotor, which consists of two precisely toothed coil bodies and permanent magnets between the teeth. The rotor and stator's teeth size is equal and determines a single step's distance. The working principle is the following: By exciting the moving part's coil it concentrates on the suitable pole the magnetic force lines. Since the magnetic force lines close in the shortest distance the moving part steps in a direction where its teeth are lined up to the stators teeth. By exciting the coils with proper polarity and order the moving part can be moved in arbitrary directions. The friction between the stator and the rotor lessens even further the efficiency. Therefore the step by step motor's moving force is limited, typically around $300 \mathrm{~N}$. It can achieve $1 \mathrm{~g}$ acceleration and up to $1.5 \mathrm{~m} / \mathrm{s}$ velocity. The repetition accuracy is $10 \mu \mathrm{m}$, and the motor does not have feedback.

\section{B. Linear DC motors}

Linear DC motors are ideal for achieving large moving distances. This type of motor is equivalent to the unfolded version of the regular rotational DC motor. This means that the stator is coiled and contains the commutators, while the brushes are on the moving part (Fig. 4) [10]. The moving part could be as simple as a metal sheet whit magnets glued to it, while the electric circuit containing the brushes is located on its side. Since the brushes are located on the moving part the electricity has to come from a flexible cable. The stator is made out of a metal sheet, where the magnetic coil's poles are located. There can be multiple variations of the linear DC motors, but the working principle is always the same. Typically they have a higher load force, namely around $1500 \mathrm{~N}$. They can achieve $5 \mathrm{~g}$ acceleration up to $4 \mathrm{~m} / \mathrm{s}$ velocity and the repetition accuracy is $10 \mu \mathrm{m}$.

\section{Linear AC induction motors}

The working principle of the linear $\mathrm{AC}$ motor is equivalent to the rotational squirrel-cage motor. They are usually used when the load has to travel a long distance with great speed and when high precision is not important (Fig. 5) [10]. 


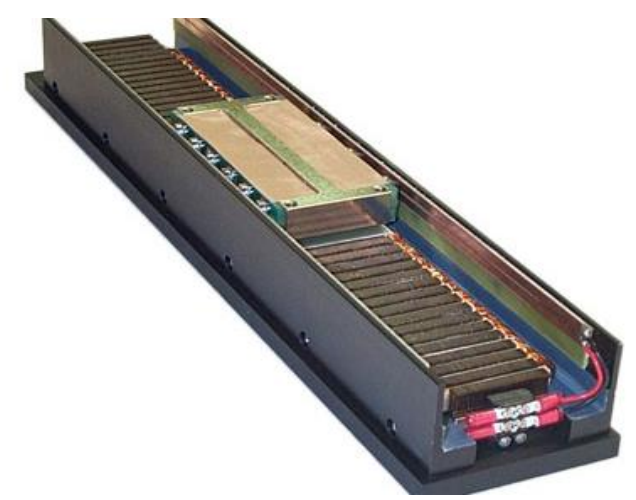

Fig. 4. Linear DC motor with brushes

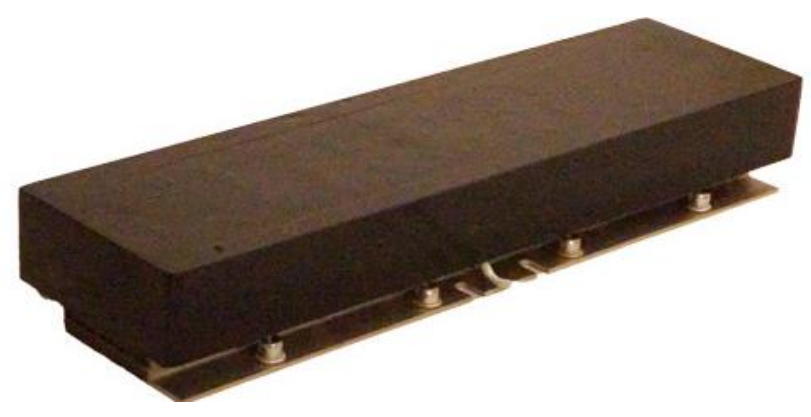

Fig. 5. Linear AC induction motor

It has two parts. The first one is sheeted steel container, which contains the coils, the other one is a two layered, so called reaction sheet provided by the user. The reaction sheet is a combination of a thin aluminum or copper sheet and a thicker steel sheet. The thickness of both parts has to be the same.

The coils are excited with three phase voltage which causes the movement. The magnetic field generates a whirling current in the reaction sheet, which also generates a magnetic field. The movement speed is proportionate to the inlet frequency and the coil sheet's pole numbers.

The coil sheets can be pared facing each other, forming a two sided motor. This way there is no need for a two layered reaction sheet, one thicker steel sheet is enough. This way we can increase the moving force. With similar construction parameters and gap the power of the two sided motor is four times the regular linear AC induction motor. The motor can be connected to the network directly, but in that case the speed is constant. Typically the load force is higher than in the case of the previously discussed motors. It is measured around $2500 \mathrm{~N}$. These motors can achieve $5 \mathrm{G}$ acceleration up to $50 \mathrm{~m} / \mathrm{s}$ velocity. The gap can be under $1 \mathrm{~mm}$.

\section{Linear Ironless BLDC motor}

The linear BLDC motors are used when smooth, precise movement is required with high power. The working principle is identical to the rotary BLDC motor, just it is the unfolded version. The magnetic field is stationary, while the coils are moving (Fig. 6) [11]. The motor consists of two parts, a U shaped profile where the magnets are glued into the inner part of the shape, and a coil holder, which contains the three phase

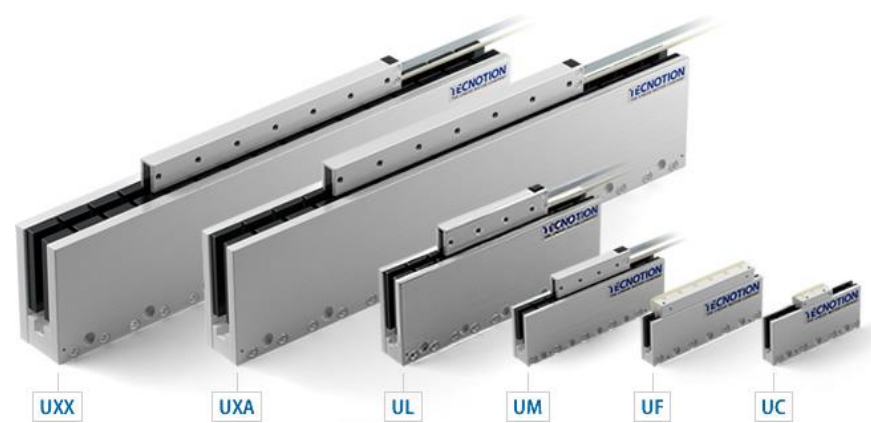

Fig. 6. Linear Ironless BLDC motors from Tecnotion

ironless magnets. Since there is no iron in the moving part, there is no magnetic attraction between the two parts. To be able to perform positional tasks, the motor has to use an external encoder. The rotary BLDC motors driver is to be used to move this motor. By putting multiple magnets one after another, the working force can be increased. Typically it is around $3000 \mathrm{~N}$. It can achieve $10 \mathrm{G}$ acceleration up to $10 \mathrm{~m} / \mathrm{s}$ velocity. The repetition precision is $1 \mu \mathrm{m}$, and the gap is less than $0.5 \mathrm{~mm}$.

\section{E. Brushless DC linear motors with iron core}

The brushless DC linear motors with iron core are used when great precision and large forces are needed. It consists of two parts, a track, where the magnets are glued one after another with different polarities, and a coil holder, where the three phased coils are located (Fig. 7) [11]. Because of the iron cores, an additional attraction is present, which is ten times greater than the working force. Typically the working force is around $15000 \mathrm{~N}$. It can achieve $10 \mathrm{G}$ acceleration up to $10 \mathrm{~m} / \mathrm{s}$ velocity. The repetition precision is $1 \mu \mathrm{m}$, and the gap is less than $0.5 \mathrm{~mm}$.

\section{F. Tubular linear motors}

Tubular linear motor is created when the regular BLDC motor is unfolded, and then folded back along the line, which is perpendicular to the magnetic field's spreading direction (Fig. 8) [12] [13]. It can be made with short and long coils, but since the long coils are expensive to make the shorter coils are more common. The moving part is usually a long tube, which has neodymium magnets in it with alternating polarities.

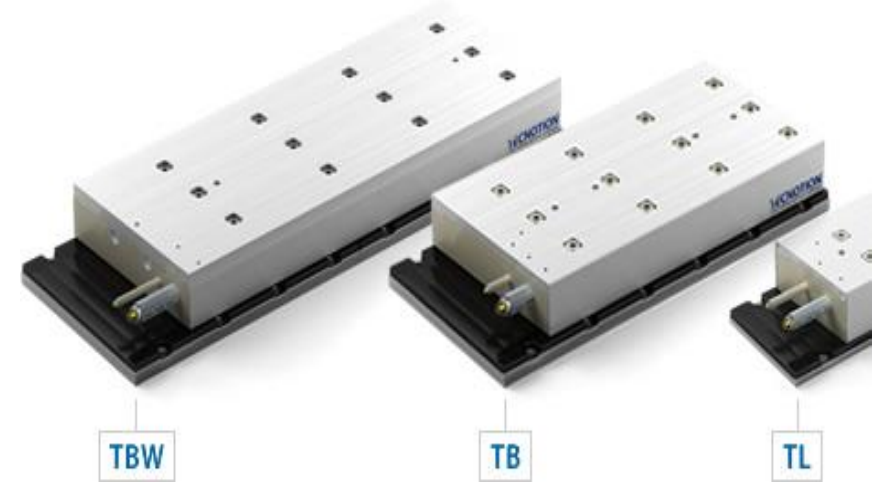

Fig. 7. Brushless DC linear motors with iron core 


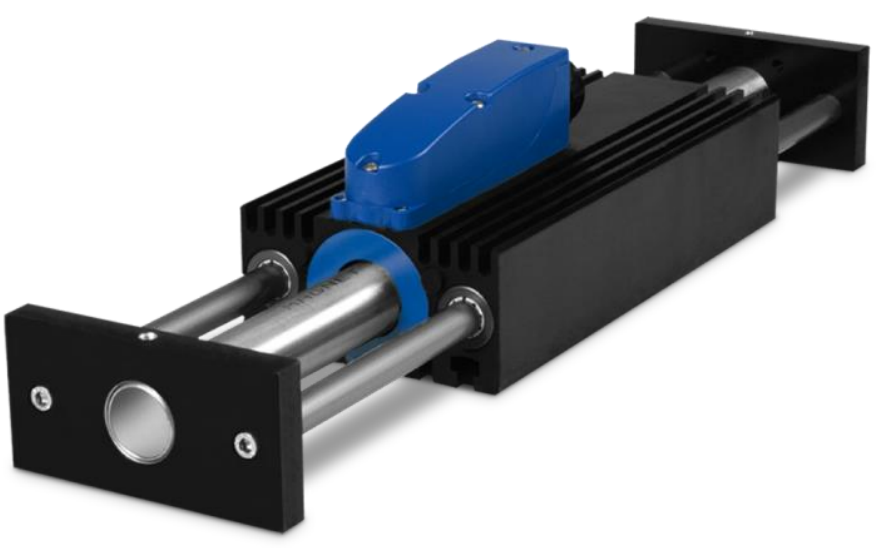

Fig. 8. Tubular linear motor

If the motor has to work in conditions, which require high precision positioning, an external encoder has to be included. Typically the working force is around $600 \mathrm{~N}$. It can achieve $20 \mathrm{G}$ acceleration up to $5 \mathrm{~m} / \mathrm{s}$ velocity [14][15]. The repetition precision is $0.05 \mu \mathrm{m}$, and the gap is less than $0.5 \mathrm{~mm}$.

\section{CONCLUSION}

The presented overview of most commonly used electromechanical linear actuators and linear motors, as well as their applications, gives an insight to the problem of achieving linear motion. It can be concluded that linear motors provide much better performance than the electromechanical linear actuators in a wide range of parameters.

In terms of velocity, efficiency, acceleration and repeatability they achieve much better performance, which is presented in Table 1.

TABLE I. COMPARISON OF LINEAR MOTORS AND ELECTROMECHANICAL DRIVES PROPERTIES

\begin{tabular}{|c|c|c|}
\hline Velocity & $\begin{array}{c}\text { Electromechanical } \\
\text { drive }\end{array}$ & Linear motor \\
\hline Acceleration & High & Very High \\
\hline Repeatability & High & Very High \\
\hline Efficiency & $\begin{array}{c}\text { Low (rotational } \\
\text { transformation) }\end{array}$ & $\begin{array}{c}\text { Very good (direct } \\
\text { drive force) }\end{array}$ \\
\hline Abrasion & Many wearing parts & No wearing parts \\
\hline $\begin{array}{c}\text { Required } \\
\text { maintenance }\end{array}$ & High & Low \\
\hline $\begin{array}{c}\text { Maintenance } \\
\text { cost }\end{array}$ & High & High \\
\hline Price & Acceptable & \\
\hline
\end{tabular}

Since linear motors have less moving parts, the required maintenance is lower than in the case of electromechanical linear actuators.

Although linear motors have multiple positive characteristics, they still fall short on some important fields. The main drawback of the linear motors is the initial cost. For example, the cost of a linear system based on linear motors is still very high. However recent trends show that in the near future price drop will occur, which implies that more and more electromechanical actuators will be replaced by linear motors.

\section{REFERENCES}

[1] I. Fürstner, L. Gogolak. "Presentation of the developed mechatronic devices for exhibition purposes." International Journal of Electrical and Computer Engineering Systems 6.1 (2015): 23-28.

[2] W. Jihong, J. Pu, and P. Moore. "A practical control strategy for servopneumatic actuator systems." Control Engineering Practice 7.12, pp. 1483-1488, 1999

[3] J. Gyeviki, J. Sárosi, S. Csikós, "Position Control of Pneumatic Actuators with PLC", IEEE/ASME International Conference on Advanced Intelligent Mechatronics (AIM 2011), Budapest, Hungary, 37 July, 2011, ISBN 978-1-4577-0837-4, ISSN 2159-6247, CD-ROM, pp. 742-747

[4] Kuroda Jena Tec Inc. "Ballscrew Linear Actuators Catalogue", web: http://www.jena-tec.com/

[5] S. Hu, F. Liu, Y. He, B. Peng, "Characteristics of additional load losses of spindle system of machine tools.", Journal of Advanced Mechanical Design, Systems, and Manufacturing 4.7, pp. 1221-1233. 2010

[6] C. Gonzalez, "What's the Difference Between Pneumatic, Hydraulic, and Electrical Actuators?", web: http://machinedesign.com

[7] FESTO, "Toothed belt based linear drive", web: www.festo.com

[8] G. Pritschow, "A comparison of linear and conventional electromechanical dives." CIRP Annals-Manufacturing Technology 47.2 pp. 541-548, 1998.

[9] A. Zsuffa, "Villamos hajtások és mozgásvezérlők - 7. rész, Lineáris motorok",Q-TECH Mérnöki Szolgáltató Kft.

[10] H2W Technologies Inc. "Linear Stepper Stages", web: http://www.h2wtech.com/

[11] Tecnotion "The linear motor company", web: http://www.tecnotion.com

[12] Dunkermotoren, "ST product cataloque', web: www.dunkermotoren.de

[13] P. K. Budig, "The application of linear motors." Power Electronics and Motion Control Conference, 2000. Proceedings. IPEMC 2000. The Third International. Vol. 3. IEEE, 2000.

[14] A. P. Balkovoi, et al. "Design of direct linear drives for manufacturing." Russian Electrical Engineering 84.7, pp. 363-369.2013.

[15] Gordon,., \& Hillery, M. T. ."Development of a high-speed CNC cutting machine using linear motors", Journal of Materials Processing Technology, 166(3), 321-329, 2015. 